International Journal of Materials Science

ISSN 0973-4589 Volume 7, Number 2 (2012), pp. 105-110

(C) Research India Publications

https://dx.doi.org/10.37622/IJoMS/7.2.2012.105-110

\title{
Corrosion Behavior of Fe-Al-C Alloy
}

\author{
Soekrisno $^{1}$ and Ratna Kartikasari ${ }^{2}$ \\ ${ }^{1}$ Department of Mechanical Engineering, \\ Faculty of Engineering, Gadjah Mada University, Yogyakarta, Indonesia \\ ${ }^{2}$ Nasional College of Technology, \\ Department of Mechanical Engineering, Yogyakarta, Indonesia
}

\begin{abstract}
Corrosion Behavior of Fe-Al-C alloy with 1.24wt-\% Al and 9.05wt-\% Al have been studied. The alloys were prepared by an induction furnace under argon atmosphere. The results showed that $\mathrm{Al}$ combines with $\mathrm{Fe}$ to form $\mathrm{FeAl}$ precipitates in $1.24 \mathrm{wt}-\% \mathrm{Al}$ alloy whereas lamellar $\mathrm{FeAl}_{2}$ was found in $9.05 \mathrm{wt}-$ $\%$ Al. The results of corrosion test showed that both the alloys are more resistant in $\mathrm{NaCl}$ than in $\mathrm{H}_{2} \mathrm{SO}_{4}$ solution. There is indication that the form of corrosion is uniform and there is no tendency toward inter granular attack.
\end{abstract}

Keywords: Corrosion Behavior; FeAl Precipitates; Lamellar $\mathrm{FeAl}_{2}$; Inter granular attack

\section{Introduction}

$\mathrm{Fe}-\mathrm{Al}-\mathrm{C}$ alloy is a good candidate for replacing some of the conventional stainless steel in several applications at moderate to high temperature ${ }^{[1]}$. Wherein, $\mathrm{Al}$ is used to substitute expensive alloy elements in conventional $\mathrm{Fe}-\mathrm{Cr}-\mathrm{C}$ system. Ferritic iron aluminum alloys shows-promising physical and mechanical properties along with superior corrosion and oxidation resistance at much lower raw material $\cos ^{[2]}$.

$\mathrm{Fe}-\mathrm{Al}$ alloys exhibit poor toughness. These are brittle at room temperature ${ }^{[3]}$. Addition of carbon to $\mathrm{Fe}-\mathrm{Al}$ containing 8.5 to $16 \mathrm{wt}-\% \mathrm{Al}$ gives higher strength ${ }^{[4]}$, and better machinability ${ }^{[5]}$. It has been shown that low carbon content $(0.05$ and $0.1 \mathrm{wt}-\%)$ in $\mathrm{Fe}$ $9 \mathrm{wt}-\%$ Al leads to low tensile ductility ${ }^{[6]}$. Whereas, the ESR (Electro Slag Refined) ingots of $\mathrm{Fe}-10.5 \mathrm{Al}$ and $\mathrm{Fe}-13 \mathrm{Al}$ alloys containing high $(0.5$ and $1.0 \mathrm{wt}-\%)$ carbon exhibit excellent hot workability ${ }^{[7]}$.

Fe-Al-C alloy is being developed for elevated temperature structural application up to $873 \mathrm{~K}^{[8]}$. 
Aluminum plays a major role in the oxidation and corrosion resistance which is characteristic of the binary $\mathrm{Fe}-\mathrm{Al}$ alloy ${ }^{[9]}$. The Fe-Al-C alloys have good corrosion resistance in a neutral environment. Its corrosion rates are comparable to that of white cast-iron in acid environments ${ }^{[10]}$. However, few data are available on the corrosion phenomena of $\mathrm{Fe}-\mathrm{Al}$ alloy in acid media like $\mathrm{H}_{2} \mathrm{SO}_{4}$.

In this Study, Corrosion Behavior of Fe-9Al-0.6C alloy have been Reported.

\section{Experimental Procedure}

Thirty five kilograms of Fe-Al-C was prepared from mild steel scrap, high purity aluminum, and $\mathrm{Mn}$ with medium $\mathrm{C}$. The alloy was prepared in an induction furnace under argon atmosphere. The chemical compositions are listed in Table 1. The ingot was cut using bimetallic band saw blade to make specimens for corrosion (14 $\mathrm{mm}$ in gauge diameter and $3 \mathrm{~mm}$ in gauge length) studies. The surface of the corrosion specimens were mechanically polished with abrasive paper up to 1200 grit, after surface finishing. The last mechanical polishing was done with $0.5 \mu \mathrm{m}$ alumina paste. The corrosion measurements were carried out with three-electrode polarization in $0.5 \% \mathrm{NaCl}$ and $0.05 \mathrm{M} \mathrm{H}_{2} \mathrm{SO}_{4}$. The corrosion type and the morphology of the oxide scale were determined by optical and scanning electron microscopes (SEM). Corrosions products were examined using EDS/EDAX.

The polished section were subsequently etched with $3.3 \% \quad \mathrm{HNO}_{3}-3.3 \%$ $\mathrm{CH}_{3} \mathrm{COOH}-0.1 \%$ HF- $93.3 \% \mathrm{H}_{2} \mathrm{O}$ by volume for micro structural examination by optical microscope.

Table 1: Chemical Composition (wt-\%) of the Alloys Tested

\begin{tabular}{|c|c|c|c|c|c|c|c|}
\hline Alloys & $\mathrm{Al}$ & $\mathrm{C}$ & $\mathrm{Mn}$ & $\mathrm{Si}$ & $\mathrm{P}$ & $\mathrm{S}$ & $\mathrm{Fe}$ \\
\hline A & 1.24 & 0.55 & 0.02 & 0.02 & 0.03 & 0.02 & Bal. \\
\hline B & 9.05 & 0.6 & 0.66 & 0.18 & 0.03 & 0.02 & Bal. \\
\hline
\end{tabular}

\section{Results and Discussion}

The Three-electrode polarization technique was used to measure corrosion rate of the alloy. The results are shown in table 2 .

Table 2: Corrosion Rate of the Fe-Al-C Alloy

\begin{tabular}{|c|c|c|c|c|}
\hline \multirow{2}{*}{ Specimen } & \multicolumn{2}{|c|}{$\mathrm{I} \operatorname{corr}\left(\mu \mathrm{A} / \mathrm{cm}^{2}\right)$} & \multicolumn{2}{c|}{$\mathrm{R}$ (mpy) } \\
\cline { 2 - 5 } & $0.5 \% \mathrm{NaCl}$ & $0.5 \% \mathrm{H}_{2} \mathrm{SO}_{4}$ & $0.5 \% \mathrm{NaCl}$ & $0.05 \mathrm{M} \mathrm{H} 2 \mathrm{SO} 4$ \\
\hline Fe-1.24Al-0.55C & 11.25 & 37.47 & 0.37 & 1.81 \\
\hline Fe-9.05Al-0.6C & 8.96 & 21.62 & 0.35 & 0.74 \\
\hline
\end{tabular}


Table 2 indicates that not only in the $0.5 \% \mathrm{NaCl}$ but also in the $0.05 \mathrm{M}$ $\mathrm{H}_{2} \mathrm{SO}_{4}$ solution, the corrosion rate of $\mathrm{Fe}-1.24 \mathrm{Al}-0.55 \mathrm{C}$ alloy is greater than that of Fe9.05Al-0.6C alloy. The difference of the corrosion rate is $15.99 \%$ and $59.35 \%$ respectively. This is primarily because of higher Aluminum content. A protective passive film was formed on the specimen surface at the stabilized corrosion potential. Figs 1 to 3, indicate that the oxide layer is rich in aluminum. The $\mathrm{X}$-ray diffraction results show that the outer region is $\mathrm{Al}_{2} \mathrm{O}_{3}$. These corrosion rates are in either excellent or good category ${ }^{[11]}$.
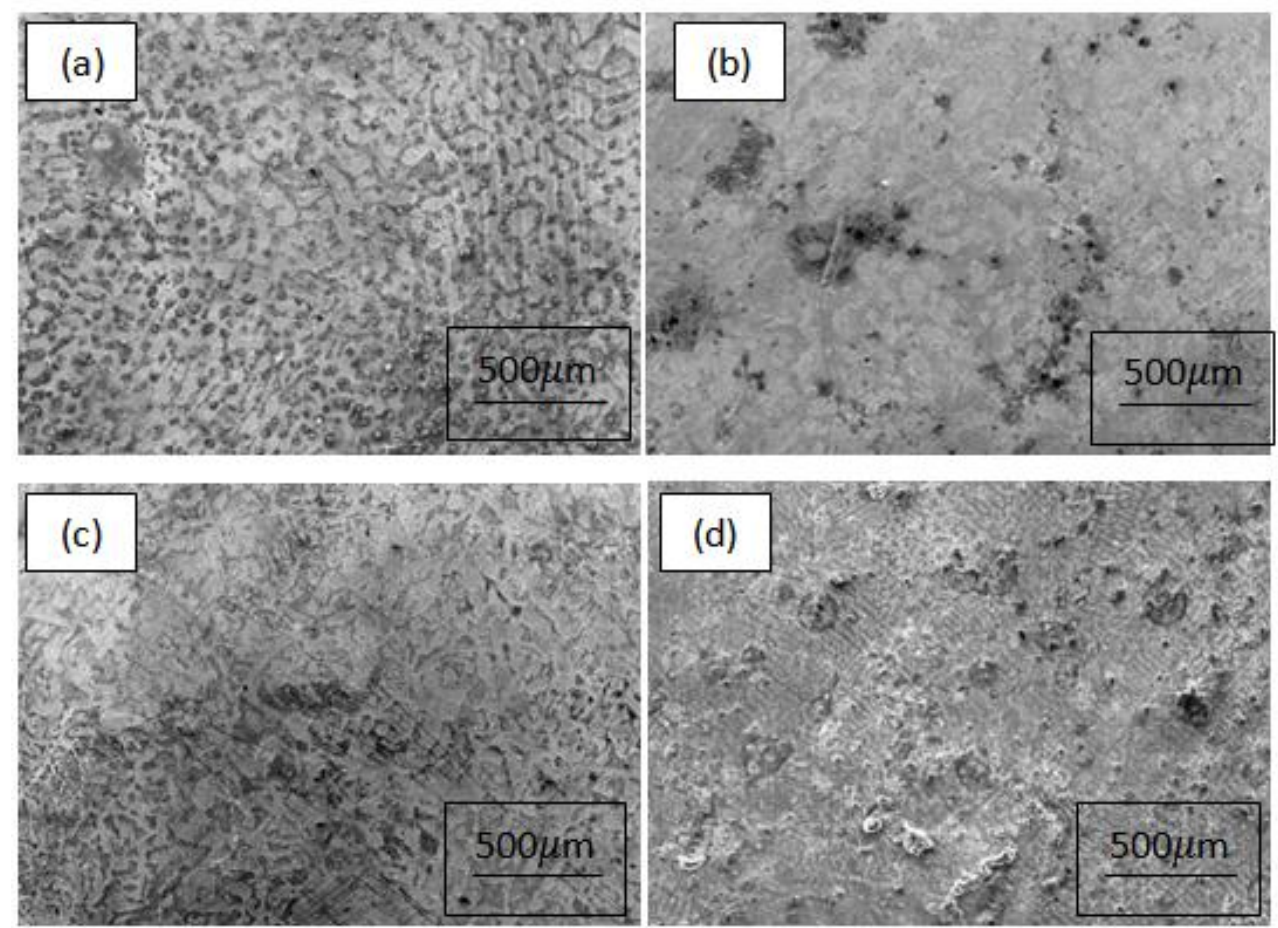

Figure 1: SEM Micrographs of as cast Fe-Al-C Alloy after Corrosion (a). Fe-1.24Al$0.55 \mathrm{C}$ in $0.05 \mathrm{M} \mathrm{H}_{2} \mathrm{SO}_{4}$ (b). Fe-1.24Al-0.55C in $0.5 \% \mathrm{NaCl}$ c. Fe-9.05Al-0.6C in 0.05 $\mathrm{M} \mathrm{H}_{2} \mathrm{SO}_{4}$ d. Fe-9.05Al-0.6C in $0.5 \% \mathrm{NaCl}$

Fig 1.shows surface corroded for the alloys. Light and dark pattern microstructures seem at 1.2\% Al. whereas, in the higher magnification (Fig.3) oxide pattern was very clear. SEM-EDS analysis (Fig 4-5) shows present some oxides like $\mathrm{Al}_{2} \mathrm{O}_{3}$ and $\mathrm{FeO}$ that are come from composition of these alloy, while $\mathrm{Na}_{2} \mathrm{O}, \mathrm{SO}_{3}$ and $\mathrm{Cl}$ are from corrosion medium. The micrograph cross section of as cast $\mathrm{Fe}-\mathrm{Al}-\mathrm{C}$ alloy after corroded show that the oxide layers formed on the surface of the alloy after corrosion testing (Fig 2). It was observed that thin oxide layer formed on the surface but internal oxidation product could not be observed. The thickness of oxide layer of $\mathrm{Fe}-1.26 \mathrm{Al}-1.05 \mathrm{C}$ alloy could be observed in both of corrosion medium but in the Fe9Al-0.6C alloy couldn't. These phenomena connected with corrosion rate. No inter granular attack could be observed in these conditions. 

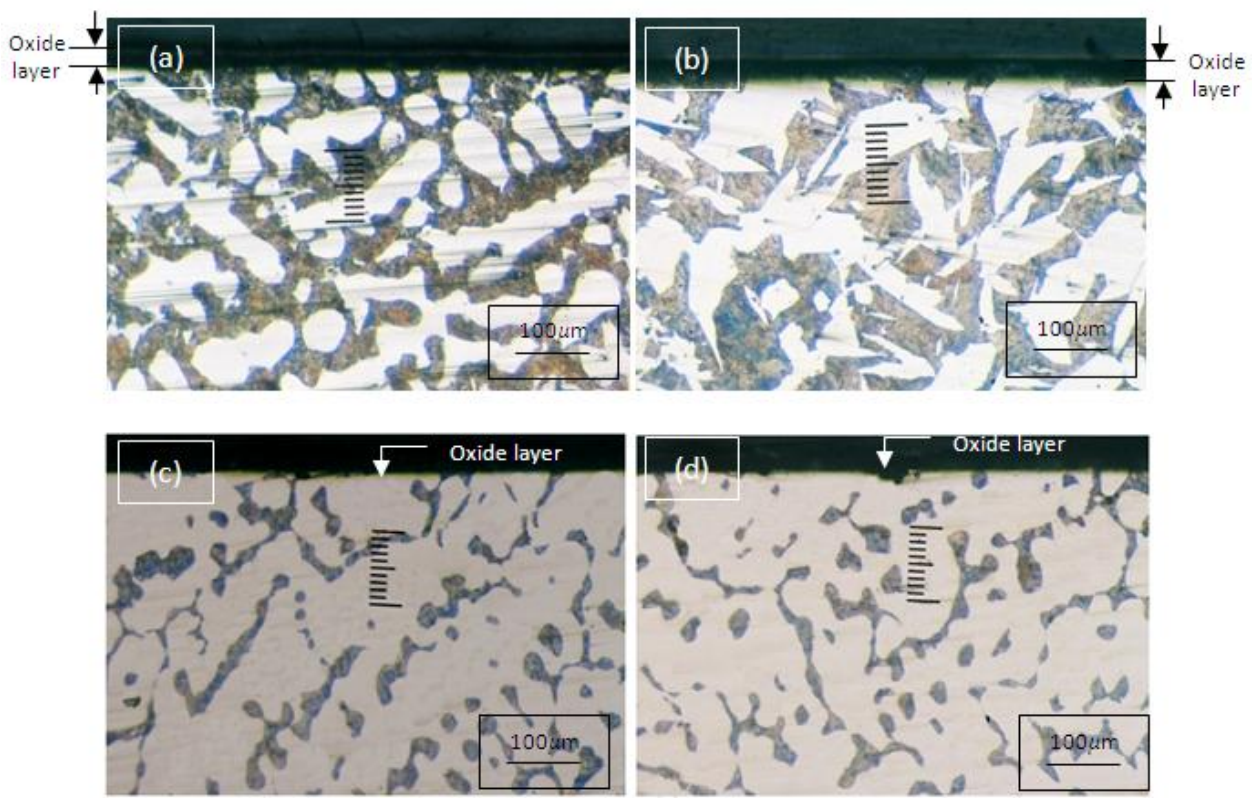

Figure 2: Metallographic cross section of as cast $\mathrm{Fe}-\mathrm{Al}-\mathrm{C}$ alloy after corrosion (a). $\mathrm{Fe}-1.24 \mathrm{Al}-0.55 \mathrm{C}$ in $0.05 \mathrm{M} \mathrm{H}_{2} \mathrm{SO}_{4}$ (b). Fe-1.24Al-0.55C in $0.5 \% \mathrm{NaCl}$ c. Fe-9.05Al$0.6 \mathrm{C}$ in $0.05 \mathrm{M} \mathrm{H}_{2} \mathrm{SO}_{4} \mathrm{~d}$. Fe-9.05Al-0.6C in $0.5 \% \mathrm{NaCl}$
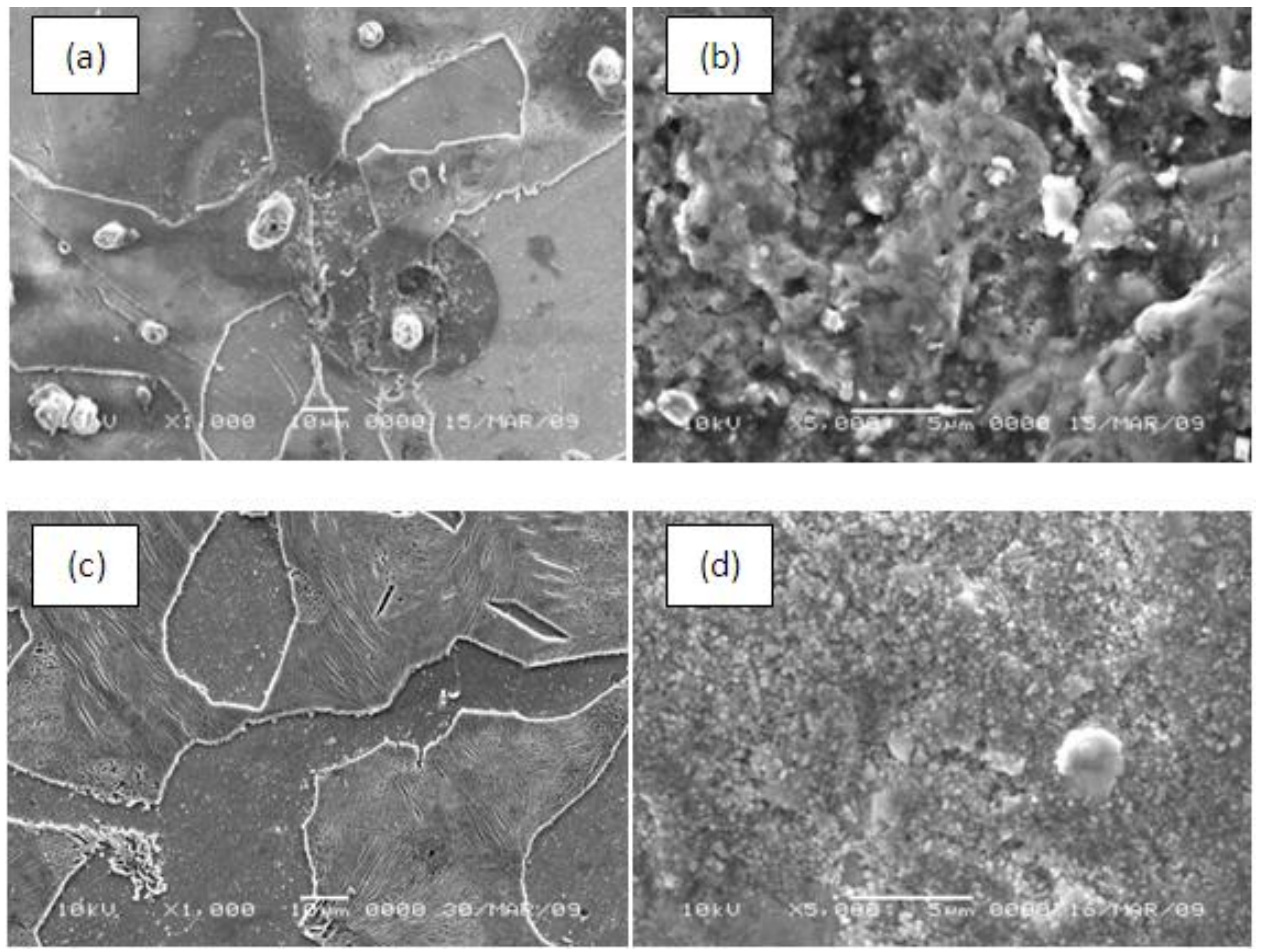

Figure 3: SEM micrographs high magnification of as cast $\mathrm{Fe}-\mathrm{Al}-\mathrm{C}$ alloy after corrosion (a). Fe-1.24Al-0.55C in $0.05 \mathrm{M} \mathrm{H}_{2} \mathrm{SO}_{4}$ (b). Fe-1.24Al-0.55C in $\mathrm{NaCl}$ c. Fe9.05Al-0.6C in $0.05 \mathrm{M} \mathrm{H}_{2} \mathrm{SO}_{4}$ d. Fe-9.05Al-0.6C in NaCl 

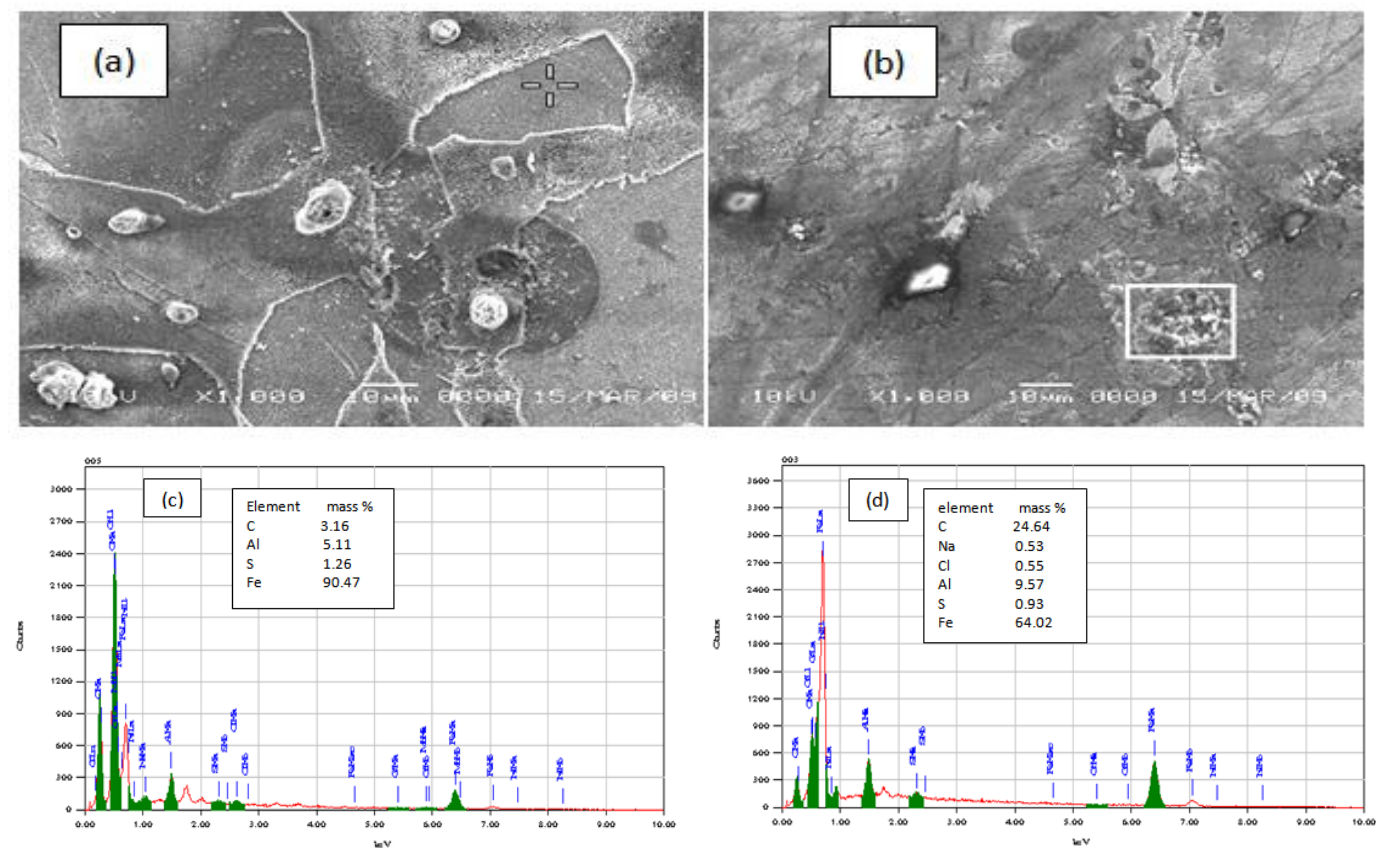

Figure 4: SEM micrographs of as cast of Fe-1.24Al-0.55Calloy after corroded (a). SE image in $0.05 \mathrm{MH}_{2} \mathrm{SO}_{4} 0.05 \mathrm{M}$ (b). SE image in $0.5 \% \mathrm{NaClc}$. EDS result in $0.05 \mathrm{MH}_{2} \mathrm{SO}_{4} 0.05 \mathrm{M}$ d. EDS result in $0.5 \% \mathrm{NaCl}$
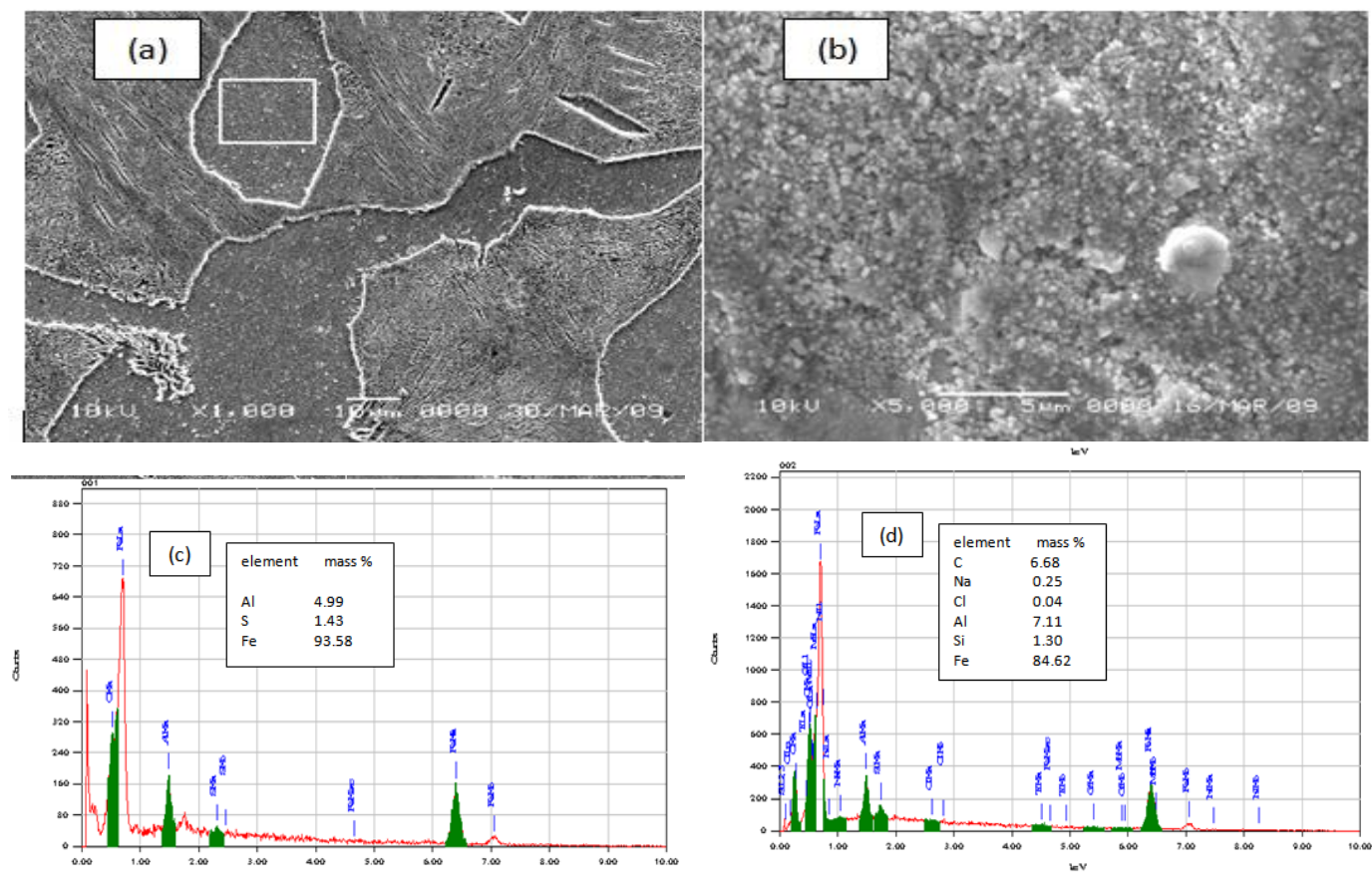

Figure 5: SEM Micrographs of as Cast of Fe-9.05Al-0.6Calloy after Corroded (a). SE image in $0.05 \mathrm{MH}_{2} \mathrm{SO}_{4} 0.05 \mathrm{M}$ (b). SE image in $0.5 \%$ NaClc. EDS Result in $0.05 \mathrm{MH}_{2} \mathrm{SO}_{4} 0.05 \mathrm{M}$ d. EDS result in $0.5 \% \mathrm{NaCl}$ 


\section{Conclusions}

The Fe-1.24Al-0.55C has uniformly distributed white colored $\mathrm{Fe}-\mathrm{Al}$ precipitates on the darker matrix while the Fe-9.05Al-0.6C alloy has lamellar white coloredFe- $\mathrm{Al}_{2}$ among a dark iron-aluminum carbide particle. General corrosion could be observed after three-electrode polarization but there is no trend toward to inter granular corrosion attack.

\section{References}

[1] Huang, Y.D., and Froyen, L., 2006, Recovery, Recrystalization, and Grain Growth in Fe3Al Based alloys, Intermetallics, Vol. 10, 443.

[2] Kobayashi, S., Zaefferer, S., Schneider, A., Raabe, D., and Frommeyer, G., Optimisation of Precipitation for Controlling Recrystallization of Wrought Fe3Al Based Alloys, Intermetallics, 2005, 13, 1296-1303.

[3] Jablonska M, RodakK, and Niewielski G, 2006, Characterization of The Microstructure of FeAl alloy after Hot Deformation, Journal of Achievements in Materials and Manufacturing Engineering, Vol. 18, Issue 1, 107-110.

[4] Baligidad RG, Prakash U, Ramakrishna Rao V, Rao PK, and Ballal NB, 1996, Effect of Carbon Content on Mechanical Properties of Electroslag Remelted Fe3Al Based Intermetallic alloys, ISIJ, Vol. 36, No. 12, 1453-1458.

[5] Baligidad RG, Prakash U, and Radha Krishna, 1998, Effect of Carbon Addition on Structure and Mechanical Properties of Electroslag Remelted Fe-20wt.\%Al alloy, Materials Science and Engineering A, Vol. 249, No. 1-2, 97-102.

[6] Stollof NS and LiuCT, 1994, Review: Environmental embrittlement of Iron Aluminides, Intermetallics, 2, pp. 75-87.

[7] BaligidadRG andSatya PrasadK, 2007, Effect of Al and C on Structure and Mechanical Properties of Fe-Al-C alloys, Mater. Sci. Technol., 23, No.1, 3844.

[8] Sikka VK, ViswanathanS, and McKameyCG, 1993, in 'Structural Intermetallic', (ed. R. Darolia et al.), Warrendale, PA, TMS. pp. 483-491

[9] Kao CH, and Wan CM, 1988, Effectof Temperature on the Oxidation of Fe7.5Al- 0.65C alloy, J. Mater. Sci., 23, 1943-1947.

[10] GizaK, Bala, H, Wysocki JJ, and SzymuraS, 1998, Corrosion Resistance of the Fe-Al-C Permanent Magnet Alloy, Intermetallics, Vol 6, issue 5, 357-362.

[11] FontanaGM, 1987, Corrosion Engineering, 3th ed., McGraw Hill Inc. Singapore, pp 153-181 